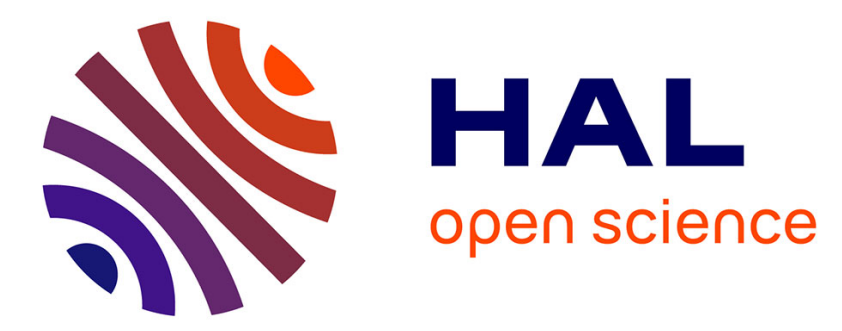

\title{
Urinary citrate: helpful to predict acid retention in CKD patients?
}

\author{
Caroline Prot-Bertoye, Marion Vallet, Pascal Houillier
}

\section{To cite this version:}

Caroline Prot-Bertoye, Marion Vallet, Pascal Houillier. Urinary citrate: helpful to predict acid retention in CKD patients?. Kidney International, 2019, 95, pp.1020 - 1022. 10.1016/j.kint.2019.01.019 . hal-03485073

\section{HAL Id: hal-03485073 \\ https://hal.science/hal-03485073}

Submitted on 20 Dec 2021

HAL is a multi-disciplinary open access archive for the deposit and dissemination of scientific research documents, whether they are published or not. The documents may come from teaching and research institutions in France or abroad, or from public or private research centers.
L'archive ouverte pluridisciplinaire HAL, est destinée au dépôt et à la diffusion de documents scientifiques de niveau recherche, publiés ou non, émanant des établissements d'enseignement et de recherche français ou étrangers, des laboratoires publics ou privés.

\section{다)(1) $(5$}

Distributed under a Creative Commons Attribution - NonCommercial| 4.0 International 
Urinary citrate: helpful to predict acid retention in CKD patients ?

Caroline Prot-Bertoye ${ }^{1-4}$, Marion Vallet ${ }^{5}$, Pascal Houillier ${ }^{1-4}$

1. INSERM UMRS 1138, Centre de Recherche des Cordeliers, Paris, France

2. CNRS, ERL 8228, Paris, France

3. Assistance Publique-Hôpitaux de Paris, Hôpital Européen Georges Pompidou, Service de Physiologie, Paris, France

4. Université Paris Descartes, Paris, France

5. Service des Explorations Fonctionnelles Physiologiques, CHU de Toulouse \& Université Paul Sabatier, Toulouse, France

Corresponding author:

Pascal Houillier, Renal and Metabolic Diseases Unit, Georges Pompidou Hospital, 20, rue Leblanc F-75015 Paris France

Phone: +33 15609 3972/+3314427 5099

Fax: +33 156092675

email: pascal.houillier@aphp.fr 
Abstract

Acid retention occurs early during the course of CKD. Studies conducted in patients with CKD suggest that alkali supplementation may slow CKD progression. However, the diagnosis of acid retention is challenging when plasma bicarbonate concentration is still normal. In this issue, Goraya et al. suggest that urinary citrate may predict acid retention in CKD stages 1 and 2, eubicarbonatemic patients. Although interesting, this claim yet requires confirmation by further studies.

Keywords: chronic kidney disease, plasma bicarbonate concentration, proximal tubule, renal acidification

Whatever its cause, chronic kidney disease (CKD) is responsible for many metabolic disorders, that, in turn, may be detrimental to the course of the kidney disease. Particularly, the prevalence of metabolic acidosis increases with the severity of the disease (1). The main reason is the impaired ability to maintain a normal acid balance that occurs early during the course of the chronic kidney disease because the capacity of the kidney to excrete the daily acid load progressively declines, mainly due to a decrease in urinary ammonia excretion.(2, 3). Of note, the acid imbalance occurs earlier than the decrease in plasma total $\mathrm{CO}_{2}$ concentration and, therefore, is present in CKD patients with normal plasma acid base parameters (3). Finally, the acid imbalance is an independent risk factor of faster rate of CKD progression and end stage renal disease (reviewed in (4)); however the risk is not linked to the lower total $\mathrm{CO}_{2}$ concentration but to the lower urinary ammonia excretion (3). 
More than thirty years ago, Nath et al studied the role of ammonia in the pathophysiology of chronic tubulo-interstitial disease in the rat. In rats having undergone subtotal nephrectomy, they showed a widespread circumferential, peritubular fluorescence for $\mathrm{C} 3$ and C5b-9; they raised the hypothesis that increased ammonia synthesis in remnant nephrons leads to high concentration of ammonia in the renal tissue that triggers the alternative complement pathway by reaction of ammonia with C3 thiolesters and initiates complement-mediated inflammation (5). Other, non exclusive, mechanisms have been proposed. Both ET-1 and aldosterone likely play a role in the adaptation of remnant nephrons to acid retention but, on the other hand, may have their own deleterious effects (4).

The $2013 \mathrm{KDIGO}$ guidelines «suggest that in people with $\mathrm{CKD}$ and $\left[\mathrm{HCO}_{3}{ }^{-}\right]$ $<22 \mathrm{mEq} / \mathrm{L}$ treatment with oral bicarbonate supplementation be given to maintain serum bicarbonate within the normal range, unless contraindicated» (6). No recommendation was made regarding CKD patients with normal plasma bicarbonate concentration.

In animal models of CKD with normal plasma bicarbonate concentration, a progressive decline in GFR occurs when dietary acid load is not reduced (reviewed in (4)). Several, small scale, prospective studies have been conducted in humans with CKD and normal plasma bicarbonate concentration; they show that alkali loading may delay CKD progression, presumably by decreasing that acid load that must be excreted in urine and, thus, improving acid balance (reviewed in (4)). Taken together, both animal and human studies support the hypothesis that CKD patients with acid retention but still normal plasma bicarbonate concentration may benefit from alkali therapy. They suggest that an early intervention in absence of overt metabolic 
acidosis is more effective than a later intervention when plasma bicarbonate concentration is low.

However demonstrating acid retention in patients with normal plasma bicarbonate concentration is challenging. Accurate balance studies require the measurement of dietary acid load, and of stool and urine net acid excretion (7), which obviously is not feasible in clinical practice. In this issue of Kidney International, Goraya et al elegantly assessed the performance of urinary citrate measurement as a marker of acid retention; the ultimate goal was to identify stage 1 and 2 CKD patients with normal plasma bicarbonate concentration but acid retention who might benefit from alkali-based therapy (8). Acid retention was estimated by the change in plasma total $\mathrm{CO}_{2}$ concentration induced by an acute oral load of sodium bicarbonate. After being absorbed by the intestine, bicarbonate is partly titrated by the free hydrogen ions present within the body, partly lost in urine (which was measured) and partly non titrated and diluted into the bicarbonate distribution space: a less marked increase in plasma total $\mathrm{CO}_{2}$ indicates that more bicarbonate has been titrated by hydrogen ions and, therefore, that baseline acid retention is greater. The authors show that the estimated acid retention is greater in stage 2 CKD than in stage 1 CKD patients, and that it decreases after 30 days on a fruit and vegetable-enriched diet in stage $2 \mathrm{CKD}$ patients. Most importantly, urinary citrate excretion follows the opposite pattern: at baseline, urinary citrate is higher in stage 1 than in stage 2 CKD patients and it increases on a fruit and vegetable-enriched diet in both groups. However, it remains lower in CKD stage 2 patients. Because urinary citrate excretion is significantly and inversely correlated with acid retention, Goraya et al. suggest measuring urinary citrate to identify whether a patient with CKD stage 1 or 2 has acid retention and may benefit from alkali-based therapy. Finally, the cutoff value of $230 \mathrm{mg} / 8 \mathrm{~h}$ has a high 
sensitivity and fair specificity, negative predictive value and accuracy to predict acid retention.

Citrate is the main organic anion in urine of mammals. Urinary citrate is the amount of filtered citrate that has not been reabsorbed by the proximal tubule, the main site of tubular citrate reabsorption along the nephron (Figure 1). The first step of citrate reabsorption is the Na-driven transport across the apical membrane mediated by the sodium-dicarboxylate cotransporter NaDC-1 (SLC13A2). Subsequently, most of citrate is metabolized by one of two pathways: the cytosolic pathway where citrate lyase metabolizes citrate into oxaloacetate and acetyl-CoA, and the mitochondrial pathway where citrate enters the citric acid cycle. Citrate metabolism consumes 2 or 3 hydrogen ions, according to the divalent or trivalent form of citrate, and generates an equal number of $\mathrm{HCO}_{3}{ }^{-}$ions. Metabolic acidosis increases the activity of the $\mathrm{Na}-$ dicarboxylate cotransporter NaDC-1 and the metabolism of citrate within the proximal tubular cell, thereby lowering the amount of citrate excreted in urine and increasing the generation of bicarbonate. As urinary citrate excretion decreases during metabolic acidosis, it is tempting to assume that it is a reliable index of acid balance, which would be quite helpful in clinical practice.

Conceptually, a lower urinary citrate excretion reflects a decrease in filtered load of citrate, of an increase in its reabsorption or a combination of both. Whether a lower urinary citrate exclusively reflects a higher citrate uptake by the proximal tubule cells adapted to a positive acid balance is uncertain, especially when GFR declines. A causal relationship between a lower urinary citrate excretion and a higher estimated acid retention in patients with lower GFR values cannot be taken for granted as long as a more comprehensive study of the changes in renal citrate handling in the condition of CKD is not available. In addition three assumptions made by the authors 
need to be critically analyzed. First, the bicarbonate load administered to the patients in order to quantify acid retention is proportional to the body weight; the implicit assumption is that the distribution space of bicarbonate is a constant fraction of the body across the various stages of CKD. This remains uncertain. A second assumption is that intestinal bicarbonate absorption following its oral administration is always complete and unaffected by CKD and/or related medication. This has not been demonstrated so far, to the best of our knowledge. The third assumption is that urinary citrate excretion has little intra-individual variation. We are not aware of any variability analysis of urinary citrate excretion in patients with CKD. The assessment of patients with renal stone disease provides some insight in this regard: the intraindividual coefficient of variation of urinary citrate excretion can be as high as $32 \%$ (9). If the same holds true for patients with CKD, it is conceivable that urinary citrate excretion values may be randomly distributed above or below the cutoff value on successive collections in the absence of any metabolic change or therapeutic intervention. Therefore, several collections might be needed before knowing whether one a given patient has normal or low urinary citrate excretion, normal acid balance or acid retention, and should or not receive alkali-based therapy. Additional causes of low urinary citrate excretion are citrate consumption by bacteria proliferating in urine, and hypokalemia that increases citrate uptake by proximal tubular cells.

The elegant approach chosen by Goraya et al. in this issue has the merit to draw attention to an unsolved and important issue, and to put forward a simple method aimed to assess acid retention in individual CKD patients. However, before implementing urinary citrate excretion in clinical practice as an index of acid retention in eubicarbonatemic patients with CKD, more work is needed to assess its performance. 


\section{Disclosure}

$\mathrm{CPB}$ has received honorarium and research support from Biohealth. $\mathrm{MV}$ and $\mathrm{PH}$ have no conflict of interest to declare.

References

1. Moranne O, Froissart M, Rossert J, Gauci C, Boffa JJ, Haymann JP, et al. Timing of onset of CKD-related metabolic complications. J Am Soc Nephrol. $2009 ; 20(1): 164-71$.

2. Goraya N, Simoni J, Sager LN, Pruszynski J, Wesson DE. Acid retention in chronic kidney disease is inversely related to GFR. Am J Physiol Renal Physiol. 2018;314(5):F985-F91.

3. Vallet M, Metzger M, Haymann JP, Flamant M, Gauci C, Thervet E, et al. Urinary ammonia and long-term outcomes in chronic kidney disease. Kidney Int. 2015;88(1):137-45.

4. Goraya N, Wesson DE. Management of the Metabolic Acidosis of Chronic Kidney Disease. Adv Chronic Kidney Dis. 2017;24(5):298-304.

5. Nath KA, Hostetter MK, Hostetter TH. Pathophysiology of chronic tubulointerstitial disease in rats. Interactions of dietary acid load, ammonia, and complement component C3. J Clin Invest. 1985;76(2):667-75. 
6. KDIGO guidelines. Chapter 3: management of progression and complications of CKD. Kidney Int suppl. 2013;3:73-90.

7. Relman AS, Lennon EJ, Lemann J, Jr. Endogenous production of fixed acid and the measurement of the net balance of acid in normal subjects. J Clin Invest. $1961 ; 40: 1621-30$.

8. Goraya NS, J.; Sager, L.N.; Madias, N.E.; Wesson, D.E. Urine citrate excretion identifies response to dietary acid reduction in eubicarbonatemic CKD patients and may reveal underlying acid retention. Kidney Int. 2019:000-.

9. Anandaram PS, De Bolla AR, Hudson PR, Davies GK, Majumdar P, Williams CP. Problems in the metabolic evaluation of renal stone disease: audit of intraindividual variation in urine metabolites. Urol Res. 2006;34(4):249-54.

Legend:

Overview of renal citrate handling

Free (ionized) citrate (Cit) circulates both as a divalent ( $\left.\mathrm{Cit}^{2-}\right)$ and a trivalent (Cit $\left.{ }^{3-}\right)$ anion, the latter being more abundant at normal plasma $\mathrm{pH}$. After being filtered at in the glomerulus, most citrate is reabsorbed in the proximal tubule. In tubular fluid, citrate is in equilibrium between its divalent and trivalent forms, depending on the luminal fluid $\mathrm{pH}$. As hydrogen ions are actively secreted by the proximal tubular cells and bicarbonate is reabsorbed, the $\mathrm{Cit}^{2-} / \mathrm{Cit}^{3-}$ ratio increases. $\mathrm{Cit}^{2-}$ crosses the apical membrane along with sodium via the secondary active Na-dicarboxylate cotransporter NaDC-1. Within the cell, most of citrate is metabolized by one of two pathways: the cytosolic pathway where ATP citrate lyase metabolizes citrate into 
oxaloacetate and acetyl-CoA, and the mitochondrial pathway where citrate enters the citric acid cycle. The metabolism of citrate generates $\mathrm{HCO}_{3}{ }^{-}$ions that are transported across the basolateral membrane to the extracellular fluid.

Metabolic acidosis increases acid secretion by the proximal tubular cells and, subsequently, the $\mathrm{Cit}^{2-} / \mathrm{Cit}^{3-}$ ratio, citrate uptake by NaDC-1, and it stimulates both the cytosolic and mitochondrial metabolic pathways. As a result, the amount of citrate excreted in urine decreases and the amount of « new » bicarbonate generated by the metabolism of citrate increases.

Urinary citrate excretion can decrease for other reasons than metabolic acidosis: various bacteria that can proliferate in urine are able to use citrate as a metabolite substrate; potassium depletion and hypokalemia increase $\mathrm{NaDC}-1$ activity and uptake of citrate by the proximal tubular cells. Conversely, lithium decreases citrate uptake by proximal tubular cells and increases urinary citrate excretion. 